\title{
INFLUÊNCIA DA VELOCIDADE DE DESLOCAMENTO NA SEMEADURA DO MILHO
}

\section{LUIZ C. GARCIA ${ }^{1}$, ROBERTO JASPER ${ }^{2}$, MÔNICA JASPER ${ }^{3}$, ALLISON J. FORNARI ${ }^{4}$, JULIUS BLUM ${ }^{5}$}

\begin{abstract}
RESUMO: Teve-se o objetivo de verificar a influência da velocidade de deslocamento na semeadura de milho, variando de 3,0 a $9,0 \mathrm{~km} \mathrm{~h}^{-1}$, em quatro condições. As variáveis analisadas foram: população de plantas emergidas, distribuição longitudinal, população com espigas e os componentes de rendimento. Concluiu-se que há aumento na percentagem de espaçamentos falhos e múltiplos e queda de espaçamentos aceitáveis ao se elevar a velocidade de semeadura. A produtividade só foi afetada quando a população de plantas com espigas foi reduzida pelo incremento de velocidade.
\end{abstract}

PALAVRAS-CHAVE: pneumático, disco perfurado horizontal, plantio direto.

\section{INFLUENCE OF SPEED INCREASING IN CORN SEEDING}

\begin{abstract}
The aim of this study was to assess the influence of planter travel speed in corn seeding, between 3.0 and $9.0 \mathrm{~km} \mathrm{~h}^{-1}$, in four different locations. The variables analyzed were: population of emerged plants, longitudinal distribution, population of plants bearing ears, and yield components. It was concluded that there is an increase in the percent of skips and multiples, and a decline in acceptable spacing as the travel speed of the planter increases. Yield was only affected when the population of plants with ears was reduced by the speed increasing.
\end{abstract}

KEYWORDS: pneumatic, horizontal seed plate, no-tillage.

\section{INTRODUÇÃO}

Na operação de semeadura, o estande adequado e a uniformidade de distribuição de sementes são apontados como fatores de grande influência na produtividade do milho (DELAFOSSE, 1986). Esses fatores podem ser afetados por inúmeras variáveis, sendo a velocidade de semeadura uma das mais importantes (KURACHI et al., 1989).

DAMBRÓS (1998) concluiu que a uniformidade de distribuição de plantas foi reduzida com o aumento da velocidade na operação de semeadura e verificou que a semeadora-adubadora pneumática apresentou maior percentual de espaçamentos aceitáveis e menor coeficiente de variação na menor velocidade testada $\left(5,0 \mathrm{~km} \mathrm{~h}^{-1}\right)$. SILVA (2000) assevera que a uniformidade de distribuição de sementes não foi influenciada pela velocidade de deslocamento na implantação de culturas de milho e soja. REIS \& ALONÇO (2001), comparando a precisão funcional de vários mecanismos dosadores estudados no Brasil, entre os anos de 1989 e 2000, concluíram que, com velocidades de semeadura acima de $7,5 \mathrm{~km} \mathrm{~h}^{-1}$, a qualidade da distribuição de sementes com mecanismos pneumáticos e disco horizontal perfurado se assemelha.

Estudando a qualidade na semeadura de milho com dosador do tipo disco perfurado horizontal, MAHL et al. (2004) concluíram que, nas velocidades de semeadura de 4,4 e $6,1 \mathrm{~km} \mathrm{~h}^{-1}$, obteve-se eficiência semelhante na distribuição de sementes de milho e significativamente melhor que na velocidade de $8,1 \mathrm{~km} \mathrm{~h}^{-1}$. A maior velocidade proporcionou menor percentual de

\footnotetext{
${ }^{1}$ Eng ${ }^{\circ}$ Agrônomo, Pós-Graduando em Proteção de Plantas, UNESP, Botucatu - SP, cgarcia@ fca.unesp.br

${ }^{2}$ Eng ${ }^{0}$ Agrônomo, Professor, Universidade Estadual de Ponta Grossa - UEPG, Ponta Grossa - PR.

${ }^{3}$ Acadêmica de Agronomia, Universidade Estadual de Ponta Grossa - UEPG, Ponta Grossa - PR.

${ }^{4}$ Engo ${ }^{\mathrm{o}}$ Agrônomo, Gerente da Fazenda Paiquerê, Piraí do Sul - PR.

${ }^{5}$ Eng ${ }^{\circ}$ Agrônomo, Gerente da Fazenda Tertak, Ponta Grossa - PR.

Recebido pelo Conselho Editorial em: 24-3-2006

Aprovado pelo Conselho Editorial em: 10-7-2006
} 
espaçamentos normais e aumento no percentual de espaçamentos múltiplos e falhos, maior coeficiente de variação e pior índice de precisão. A variação da velocidade não interferiu na população inicial de plantas.

SILVA et al. (2000) conduziram trabalho em solo com sistema de plantio direto para verificar o estabelecimento da cultura do milho com semeadora-adubadora equipada com dosador de sementes do tipo disco horizontal perfurado, nas velocidades de deslocamento de 3,0; 6,0; 9,0 e $11,2 \mathrm{~km} \mathrm{~h}^{-1}$. O número de plantas de milho na linha de semeadura foi menor nas maiores velocidades de operação da máquina. A uniformidade dos espaçamentos entre as sementes de milho na linha de semeadura foi considerada excelente para a velocidade de $3,0 \mathrm{~km} \mathrm{~h}^{-1}$, regular para 6,0 e $9,0 \mathrm{~km} \mathrm{~h}^{-1}$ e insatisfatória para $11,2 \mathrm{~km} \mathrm{~h}^{-1}$. As velocidades da semeadora-adubadora de até $6,0 \mathrm{~km} \mathrm{~h}^{-1}$ propiciaram maiores estandes de plantas e número de espigas por metro e foram responsáveis pelos maiores rendimentos de grãos.

FURLANI et al. (1999) concluíram que, quando a velocidade de semeadura passou de 3 para $5 \mathrm{~km} \mathrm{~h}^{-1}$, o estande final e a produtividade de grãos foram reduzidos. FEY et al. (2000) afirmaram que o aumento da velocidade na operação de semeadura de milho influenciou na uniformidade de distribuição longitudinal de plantas, porém não afetou a população de plantas e a produtividade de grãos.

O objetivo deste trabalho foi avaliar a relação entre a distribuição de sementes e os componentes de rendimento da cultura do milho com a variação da velocidade de semeadura.

\section{MATERIAL E MÉTODOS}

A cultura do milho foi implantada na região dos Campos Gerais, Estado do Paraná, $25^{\circ} 16^{\prime}$ de latitude sul e $50^{\circ} 16^{\prime}$ de longitude oeste, clima $\mathrm{Cfb}$, em sistema plantio direto, com diferentes situações, nas quatro propriedades analisadas.

Na Fazenda Tertak, em Ponta Grossa, Latossolo Vermelho-Amarelo eutrófico, havia, no momento da semeadura, 4,2 $\mathrm{t} \mathrm{ha}^{-1}$ de palhada de aveia-preta (Avena strigosa) manejada quimicamente na fase de grão leitoso, 57 dias antes da semeadura do híbrido 30R50, com 90\% de germinação e $98 \%$ de pureza. O trator utilizado foi o John Deere $6600-88,2 \mathrm{~kW}$ (120 cv). A semeadora-adubadora empregada foi a pneumática SLC 911, equipada com seis unidades de semeadura, espaçadas entre si em $0,80 \mathrm{~m}$, com disco de 30 orifícios, pressão de 0,63 MPa, pneu com 2,50 m de circunferência, relação de engrenagens para sementes 1,00 , mecanismo de abertura de sulco do adubo com disco simples, tubo condutor de adubo tipo eso (botinha) e mecanismo de abertura do sulco da semente com disco duplo desencontrado de $0,33 \mathrm{~m}$ de diâmetro.

Na Fazenda Santa Cruz, em Ponta Grossa, Latossolo Vermelho eutrófico, no momento da semeadura, havia $4,8 \mathrm{t} \mathrm{ha}^{-1}$ de palhada de aveia-preta manejada mecanicamente na fase de grão leitoso, 59 dias antes da semeadura do híbrido 30R50, com 93\% de germinação e 99\% de pureza. O trator utilizado foi o John Deere 7500 - $103 \mathrm{~kW}(140 \mathrm{cv})$. A semeadora-adubadora usada foi a pneumática SLC 913, equipada com sete unidades de semeadura, espaçadas entre si em 0,80 m, com disco de 30 orifícios, pressão de $0,80 \mathrm{MPa}$, pneu com 2,82 m de circunferência, relação de engrenagens para sementes 0,69, mecanismo de abertura de sulco do adubo e semente com disco duplo desencontrado de $0,33 \mathrm{~m}$ de diâmetro.

Na Fazenda Mutuca, em Arapoti, Latossolo Vermelho eutrófico, havia, no momento da semeadura, 5,8 t ha ${ }^{-1}$ de palhada de trigo (Triticum aestivum) colhido três dias antes da semeadura do híbrido 30R50, com 95\% de germinação e 99\% de pureza. O trator era o CBT 8060 - 73,5 kW $(100 \mathrm{cv})$. A semeadora-adubadora foi a SSM 27, equipada com seis unidades de semeadura, espaçadas entre si em $0,80 \mathrm{~m}$, com disco perfurado horizontal de 28 orifícios, pneu com 3,69 m de circunferência, relação de engrenagens para sementes 1,40 , disco de corte liso de $0,36 \mathrm{~m}$ de diâmetro, sulcadores de adubo do tipo "facão" com ponteiras de 0,025 m de largura e ângulo de ataque de $20^{\circ}$ (guilhotina), mecanismo de abertura do sulco da semente com disco duplo desencontrado de $0,33 \mathrm{~m}$ de diâmetro. 
Na Fazenda Paiquerê, em Piraí do Sul, Latossolo Vermelho eutrófico, havia, no momento da semeadura, 3,7 t ha ${ }^{-1}$ de palhada de aveia-preta manejada quimicamente na fase de grão leitoso, 72 dias antes da semeadura, híbrido 30F53, com 93\% de germinação e $98 \%$ de pureza. O trator utilizado foi o John Deere 7500 - $103 \mathrm{~kW}(140 \mathrm{cv})$. A semeadora-adubadora empregada era a pneumática SLC 913, com sete unidades de semeadura, espaçadas entre si em 0,80 m, com disco de 30 orifícios, pressão de $0,80 \mathrm{MPa}$, pneu com 2,82 m de circunferência, relação de engrenagens para sementes 0,67 , disco de corte liso de 0,36 m de diâmetro, sulcadores de adubo do tipo "facão" com ponteiras de $0,025 \mathrm{~m}$ de largura e ângulo de ataque de $20^{\circ}$ (guilhotina), mecanismo de abertura do sulco da semente com disco duplo desencontrado de $0,33 \mathrm{~m}$ de diâmetro.

Todas as semeadoras foram reguladas para que a semente fosse distribuída a $0,05 \mathrm{~m}$ de profundidade, com o fertilizante depositado a $0,05 \mathrm{~m}$ ao lado e abaixo da semente. $\mathrm{O}$ fechamento do sulco de todas as semeadoras era do tipo roda duplo-angulada em "V" de $0,31 \mathrm{~m}$ de diâmetro. Os depósitos de adubo e de semente foram abastecidos a $50 \%$ de sua capacidade. O teor médio de água no solo na camada de 0 a 0,1 m, foi de 32; 28; 26 e 30\%, para as Fazendas Tertak, Santa Cruz, Mutuca e Paiquerê, respectivamente.

Em cada propriedade, o delineamento experimental foi em blocos casualizados, nas velocidades de deslocamento de 3;5; 7 e $9 \mathrm{~km} \mathrm{~h}^{-1}$, com seis repetições por tratamento. As velocidades foram alcançadas com o escalonamento de marcha e aferidas com o auxílio de um GPS marca Garmin, modelo Etrex, embarcado nos diferentes tratores utilizados no experimento. Considerou-se como repetição a coleta de dados em três linhas de semeadura de $10 \mathrm{~m}\left(24 \mathrm{~m}^{2}\right)$. O tamanho da amostra levou em consideração a estabilização da média e do desvio-padrão das variáveis analisadas, conforme método proposto por KRANZ (1988).

As variáveis estudadas logo após a emergência foram população e distribuição longitudinal (espaçamentos falhos, múltiplos e aceitáveis). Na colheita, registraram-se a população com espigas, número de grãos por espiga, peso de mil grãos e produtividade.

A distribuição longitudinal deu-se pela análise dos espaçamentos entre as plantas, com 20 dias após a emergência (DAE). As avaliações foram embasadas nas recomendações da ASSOCIAÇÃO BRASILEIRA DE NORMAS TÉCNICAS (1989), que considera como aceitáveis todos os espaçamentos entre plantas de 0,5 e $1,5 \mathrm{vez}$ o espaçamento médio (EM) esperado. Os valores obtidos fora desse limite foram considerados como espaçamentos falhos (acima de 1,5 vez EM) ou múltiplos (abaixo de 0,5 vez EM).

A colheita, a contagem de grãos por espiga, a debulha e a contagem de mil grãos foram realizadas manualmente. $\mathrm{O}$ peso de mil grãos e a produtividade tiveram seus valores corrigidos para $13 \%$ de umidade.

Aplicou-se o teste de Hartley para a verificação da homocedasticidade das variâncias. Os valores levantados foram submetidos à análise estatística, empregando-se os testes "F" e regressão polinomial.

\section{RESULTADOS E DISCUSSÃO}

O teste de Hartley apontou a homocedasticidade das variâncias para todas as variáveis estudadas. Portanto, não houve necessidade de transformação das médias para aplicação do teste "F". A população mensurada (20 DAE) não apresentou diferenças significativas para os experimentos instalados nas Fazendas Santa Cruz e Paiquerê, com médias de 80.600 e 78.234 plantas ha $^{-1}$. Já os resultados das Fazendas Tertak e Mutuca foram significativas, com a população decrescendo com o aumento da velocidade (Figura 1).

Assim, verifica-se que a população pode ser mantida mesmo com o incremento da velocidade, conforme concluíram FEY et al. (2000) e MAHL et al. (2004). Os dois casos em que a população decresceu com a elevação da velocidade, resultados também obtidos por SILVA et al. (2000), podem estar relacionados à regulagem da semeadora-adubadora. 

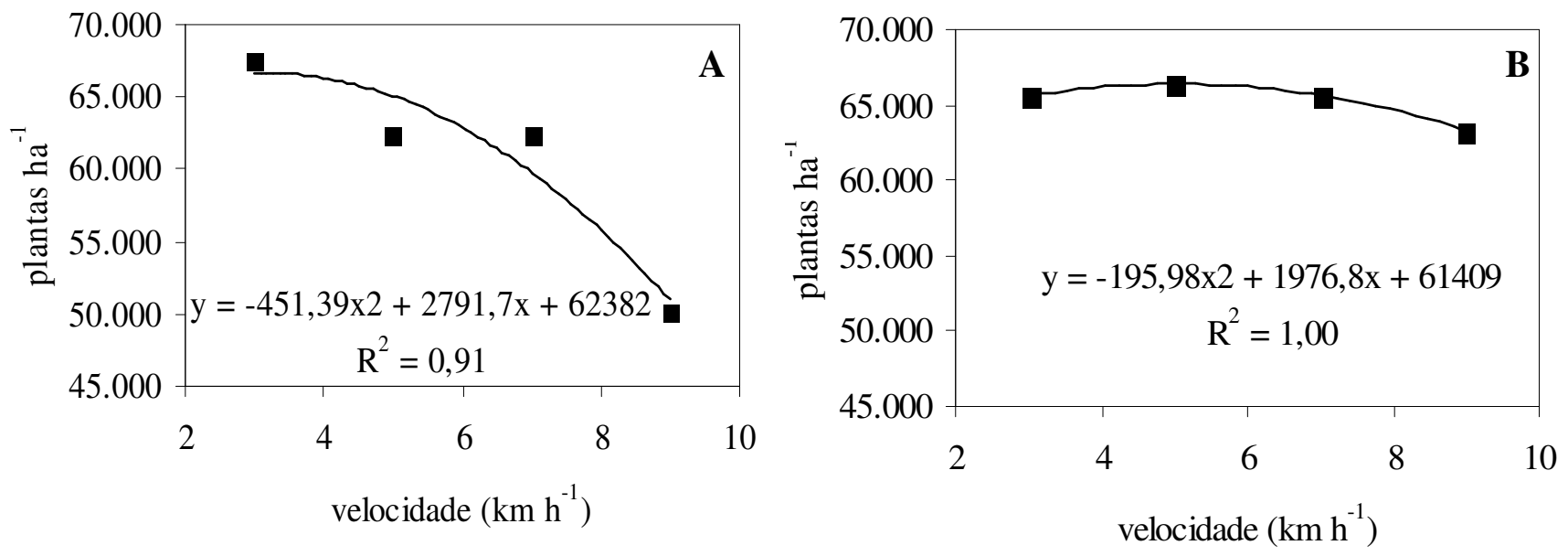

FIGURA 1. População de plantas de milho, 20 dias após a emergência, semeadas em diferentes velocidades com vários modelos de semeadoras-adubadoras, nas Fazendas Tertak Ponta Grossa (A) e Mutuca - Arapoti (B).

Em relação à distribuição longitudinal, em todas as propriedades, a regressão polinomial foi significativa, com acréscimo de espaçamentos falhos (Figura 2) e múltiplos (Figura 3) e decréscimos de espaçamentos aceitáveis (Figura 4). Tais resultados reforçam o consenso entre os pesquisadores (DELAFOSSE, 1986; KURACHI et al., 1989; DAMBRÓS, 1998; FEY et al., 2000; SILVA et al., 2000 e MAHL et al., 2004) de que a elevação da velocidade de semeadura reduz a qualidade da distribuição de sementes. A exceção encontrada na revisão bibliográfica é a conclusão obtida por SILVA (2000).
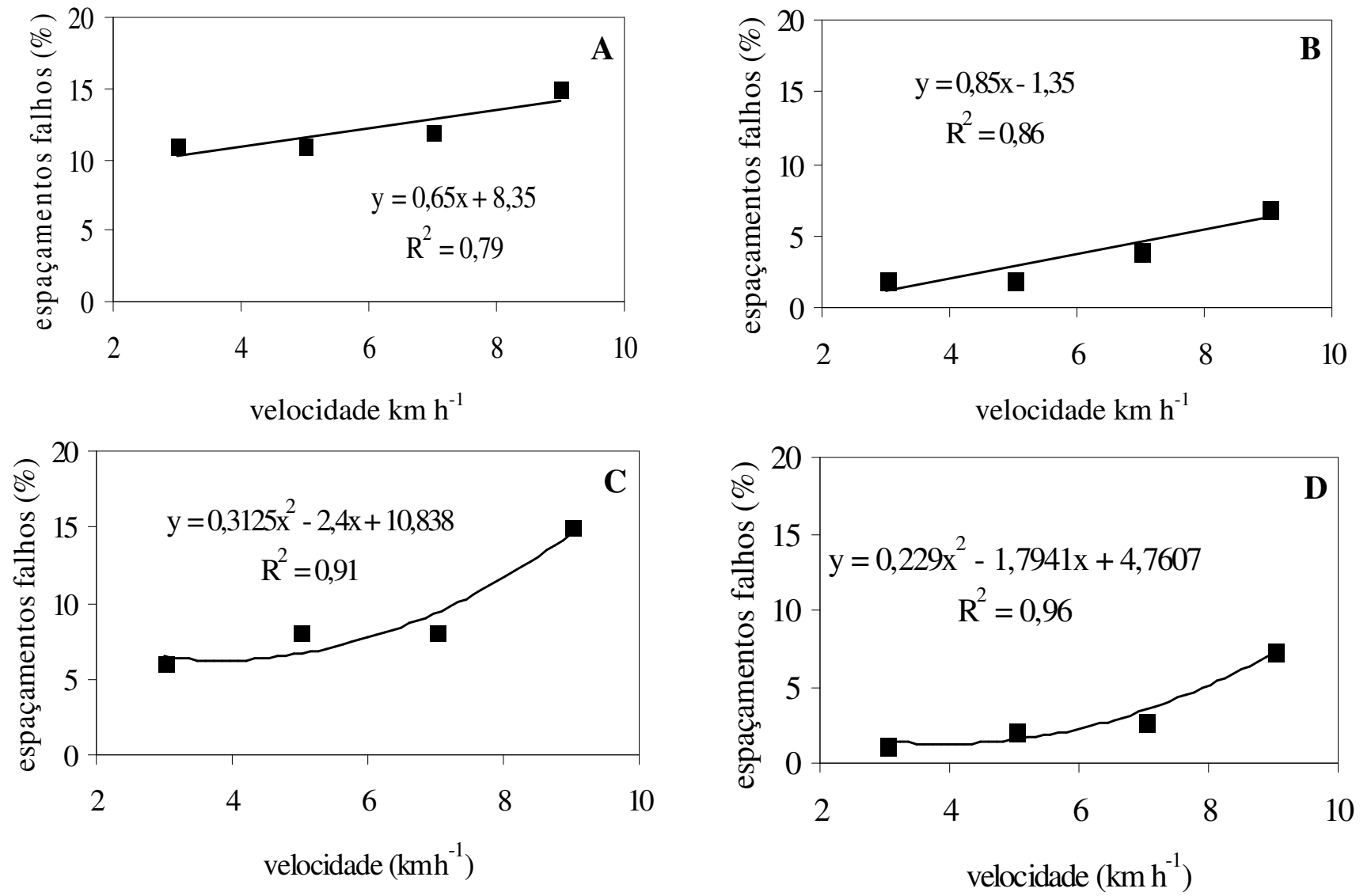

FIGURA 2. Espaçamentos falhos de plantas de milho, 20 dias após a emergência, semeadas em diferentes velocidades com vários modelos de semeadoras-adubadoras, nas Fazendas Tertak (A) e Santa Cruz - Ponta Grossa (B), Mutuca - Arapoti (C) e Paiquerê - Piraí do Sul (D). 

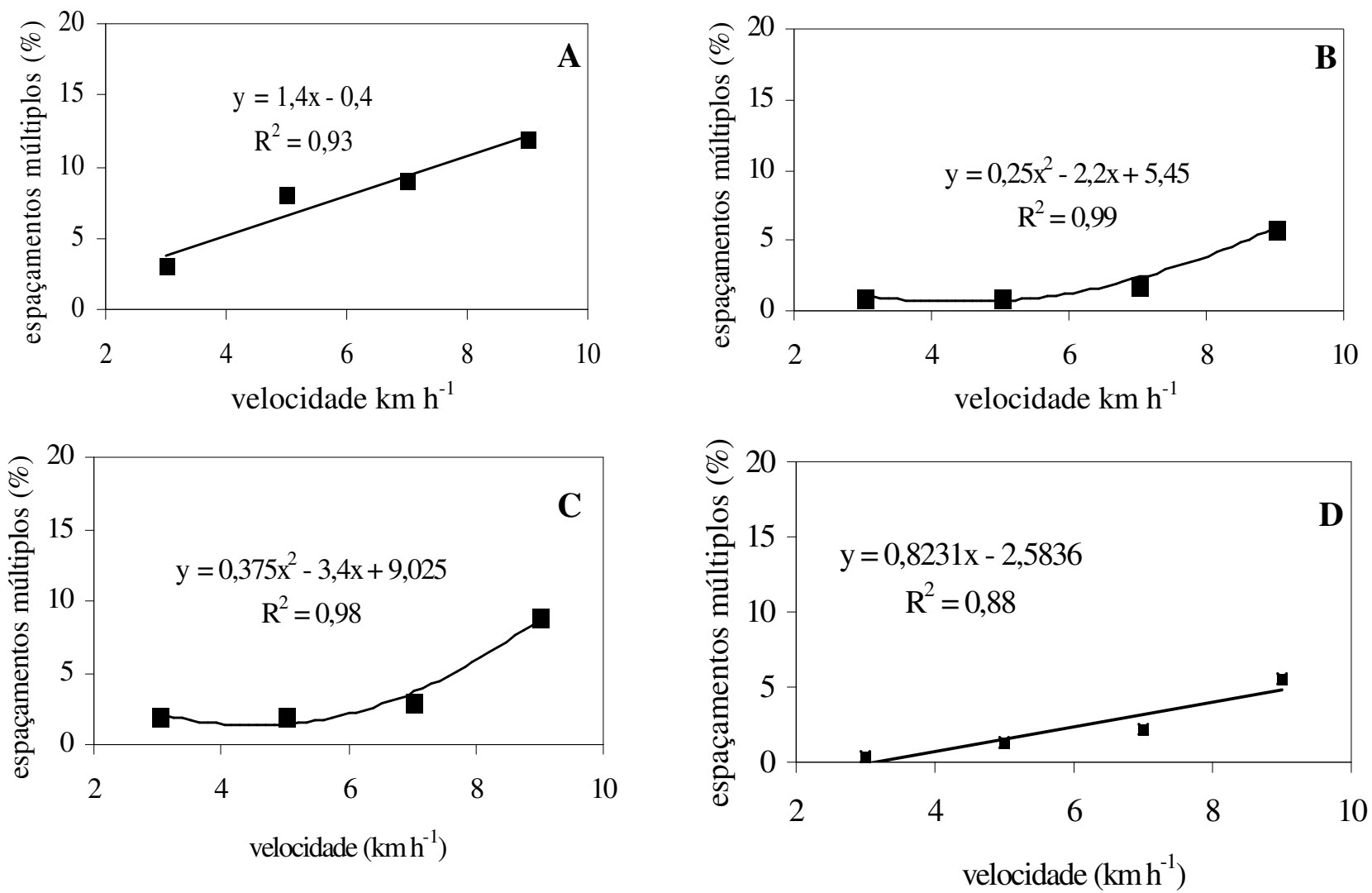

FIGURA 3. Espaçamentos múltiplos de plantas de milho, 20 dias após a emergência, semeadas em diferentes velocidades com vários modelos de semeadoras-adubadoras, nas Fazendas Tertak (A) e Santa Cruz - Ponta Grossa (B), Mutuca - Arapoti (C) e Paiquerê - Piraí do Sul (D).
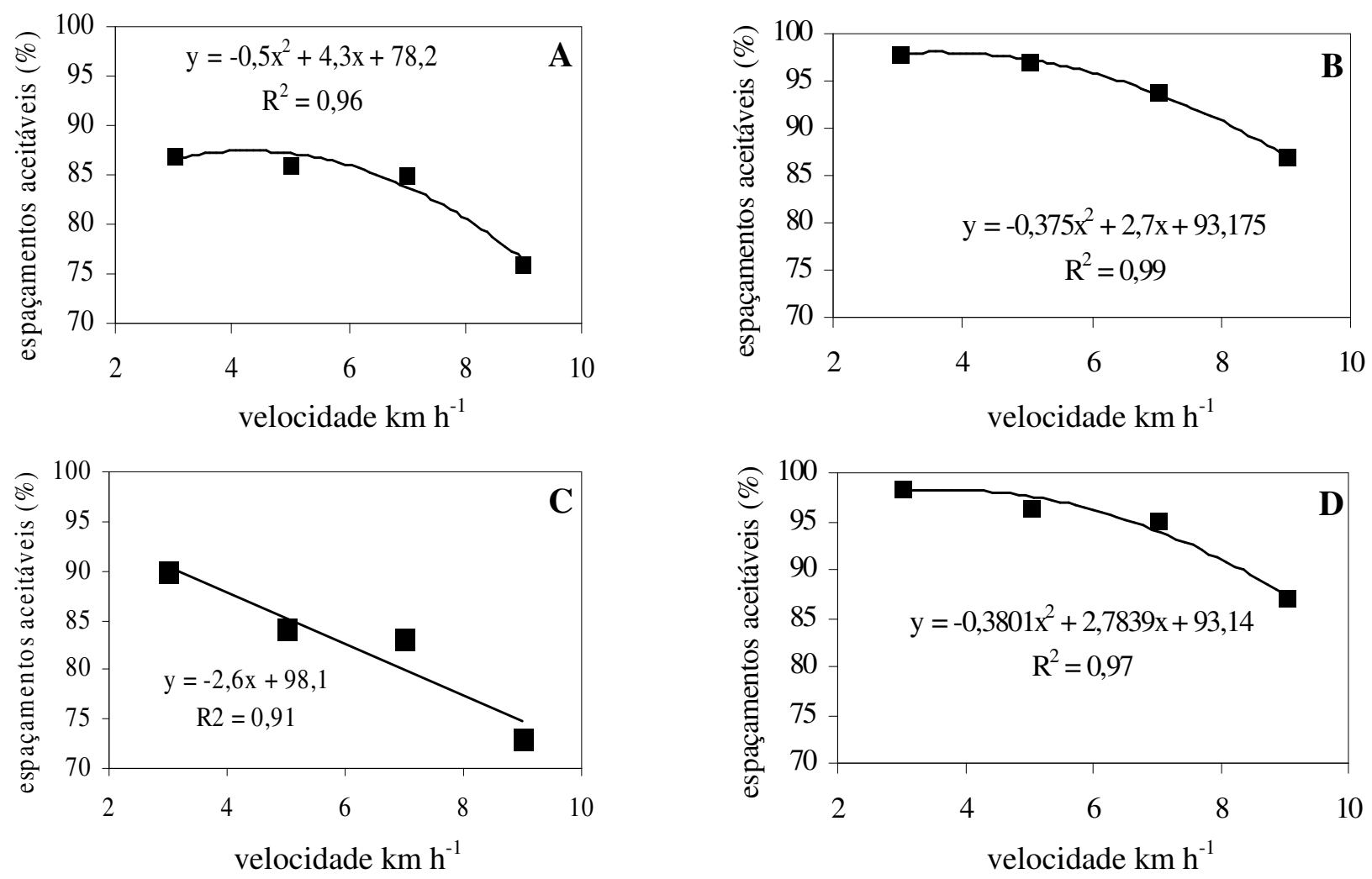

FIGURA 4. Espaçamentos aceitáveis de plantas de milho, 20 dias após a emergência, semeadas em diferentes velocidades com vários modelos de semeadoras-adubadoras, nas Fazendas Tertak (A) e Santa Cruz - Ponta Grossa (B), Mutuca - Arapoti (C) e Paiquerê - Piraí do Sul (D). 
Não houve diferença significativa entre as variâncias das médias das populações de plantas com espigas, nas diferentes velocidades testadas, para as Fazendas Santa Cruz, Mutuca e Paiquerê, com as respectivas médias de $75.417,61.145$ e 71.171 plantas ha $^{-1}$. A exceção foi a Fazenda Tertak, onde houve decréscimo significativo da população de plantas com espigas ao se elevar a velocidade de semeadura (Figura 5).

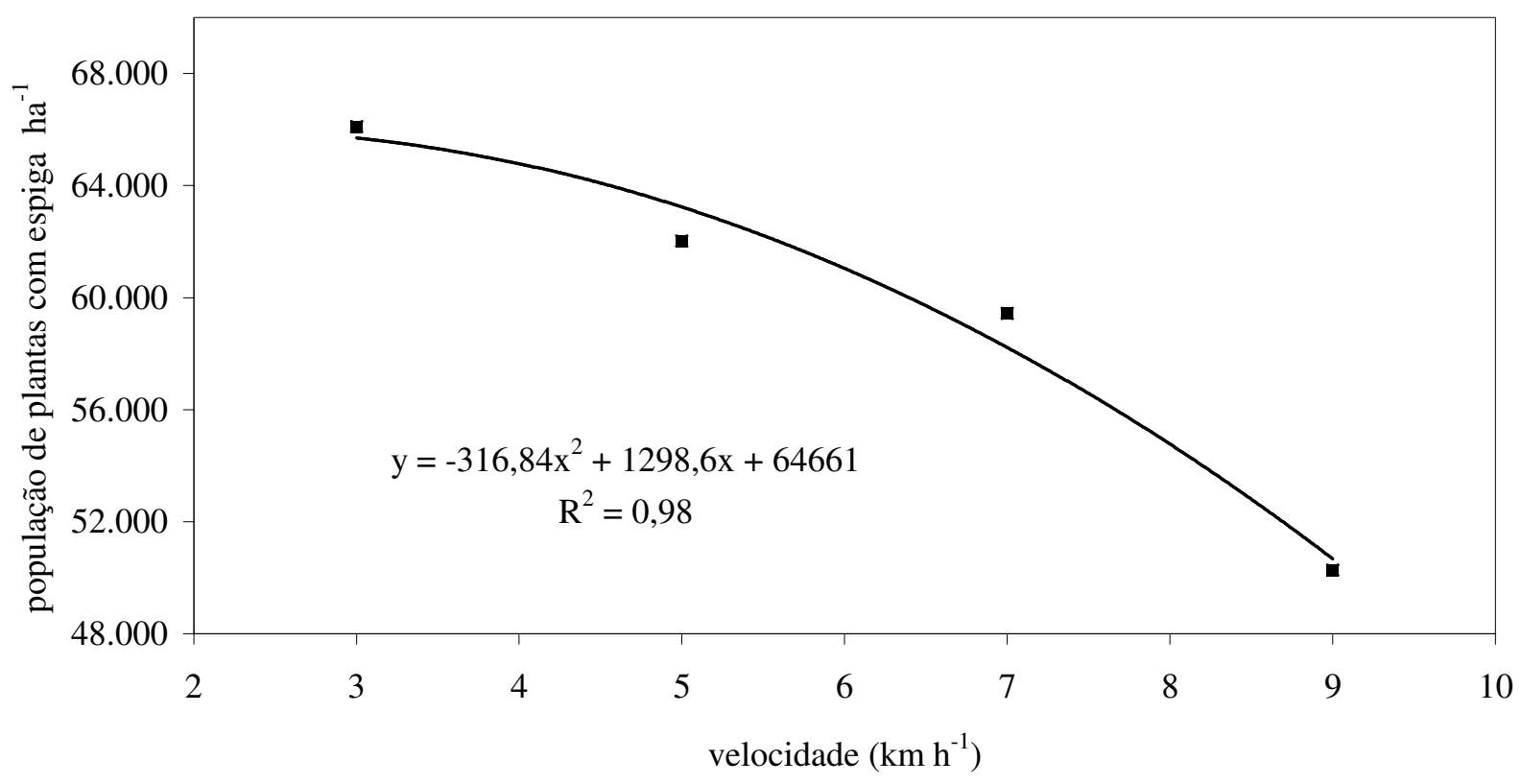

FIGURA 5. População de plantas com espigas no momento da colheita, semeadas em diferentes velocidades, com semeadora-adubadora pneumática SLC 911, na Fazenda Tertak (Ponta Grossa - PR).

Comparando a população inicial com a população com espigas no momento da colheita, observa-se que os resultados foram similares, exceto na Fazenda Mutuca, onde a variação significativa inicial não se manteve. Os dados confirmam as conclusões de MAHL et al. (2004) e FEY et al. (2000) e contradizem os resultados obtidos por SILVA et al. (2000) e REIS \& ALONÇO (2001).

A análise das médias do número de grãos por espiga não foi significativa no teste "F" para as Fazendas Tertak (474 grãos espiga ${ }^{-1}$ ), Santa Cruz (403 grãos espiga ${ }^{-1}$ ), Mutuca (443 grãos espiga ${ }^{-1}$ ) e Paiquerê (384 grãos espiga ${ }^{-1}$ ). A variável peso de mil grãos também não foi significativa em todas as áreas onde o experimento foi instalado; sendo as médias de 0,458;0,376;0,427 e 0,382 kg nas Fazendas Tertak, Santa Cruz, Mutuca e Paiquerê, respectivamente.

A variância entre as médias da produtividade não foi significativa pelo teste " $F$ " para as Fazendas Santa Cruz (11.388 kg ha $\left.{ }^{-1}\right)$, Mutuca (11.516 kg ha ${ }^{-1}$ ) e Paiquerê (10.424 kg ha $\left.{ }^{-1}\right)$. Os resultados foram significativos somente na Fazenda Tertak (Figura 6).

Os resultados indicam que a velocidade de semeadura só afeta a produtividade quando há alteração significativa da população com espiga no momento da colheita, conforme ocorreu na Fazenda Tertak (Figuras 3 e 4). Assim, os dados obtidos neste experimento contestam as conclusões de DELAFOSSE (1986) e KURACHI et al. (1989) e corroboram as afirmações de FEY et al. (2000). 


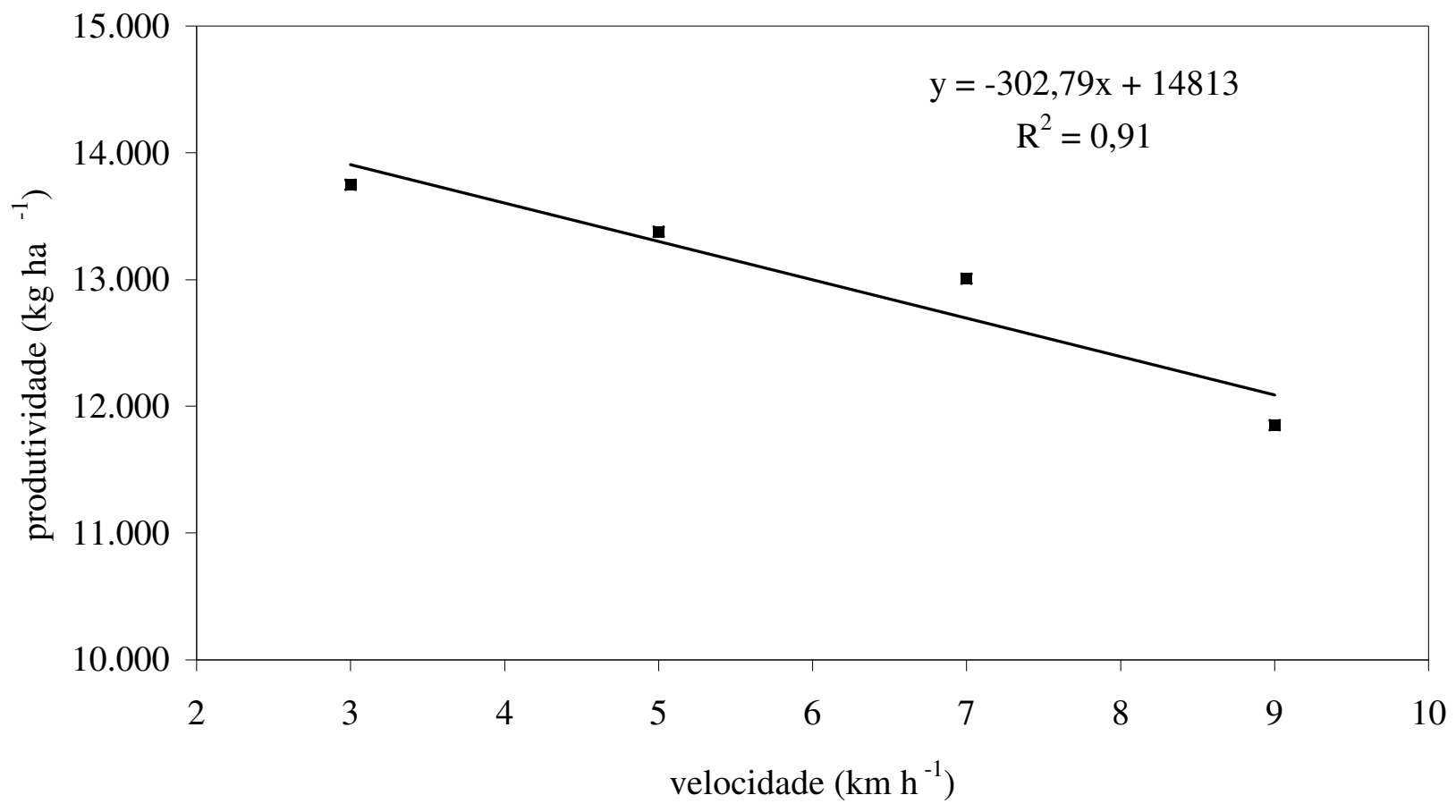

FIGURA 6. Produtividade da cultura do milho em diferentes velocidades com semeadoraadubadora pneumática SLC 911, na Fazenda Tertak (Ponta Grossa - PR).

\section{CONCLUSÕES}

Houve aumento na percentagem de espaçamentos falhos e múltiplos e queda de espaçamentos aceitáveis ao se elevar a velocidade de deslocamento da semeadora-adubadora.

A produtividade só foi afetada quando a população de plantas com espigas foi reduzida pelo incremento de velocidade.

\section{REFERÊNCIAS}

ASSOCIAÇÃO BRASILEIRA DE NORMAS TÉCNICAS. Semeadora de precisão: ensaio de laboratório/método de ensaio. Projeto de norma 12:02.06-004. Rio de Janeiro, 1989. 21 p.

DAMBRÓS, R.M. Avaliação do desempenho de semeadoras-adubadoras de milho com diferentes mecanismos dosadores. 1998. 86 f. Dissertação (Mestrado em Máquinas Agrícolas) - Escola Superior de Agricultura “Luiz de Queiroz”, Universidade de São Paulo, Piracicaba, 1998.

DELAFOSSE, R.M. Máquinas sembradoras de grano grueso: descripción y uso. Santiago: Oficina Regional de La FAO para America Latina y el Caribe, 1986. 48 p.

FEY, E.; SANTOS, S.R.; FEY, A. Influência da velocidade de semeadura sobre a produtividade de milho (Zea mays L.). In: CONGRESSO BRASILEIRO DE ENGENHARIA AGRÍCOLA, 29., 2000, Fortaleza. Anais... Fortaleza: Sociedade Brasileira de Engenharia Agrícola, 2000. 1 CDROM.

FURLANI, C.E.A.; LOPES, A.; ABRAHÃO, F.Z.; LEITE, M.A.S. Características da cultura do milho (Zea mays L.) em função do tipo de preparo do solo e da velocidade de semeadura. Engenharia Agrícola, Jaboticabal, v.19, n.2, p.177-86, 1999.

KRANZ, J. Measuring plant disease. In: KRANZ, J.; ROTEM, J. (Ed.). Experimental techniques in plant disease epidemiology. Heidelberg: Springer, 1988. p.35-50.

KURACHI, S.A.H.; COSTA, J.A.S.; BERNARDI, J.A.; COELHO, J.L.D.; SILVEIRA, G.M.

Avaliação tecnológica de semeadoras e/ou adubadoras: tratamento de dados de ensaio e 
regularidade de distribuição longitudinal de sementes. Bragantia, Campinas, v.48, n.2, p.249-62, 1989.

MAHL, D.; GAMERO, C.A.; BENEZ, S.H.; FURLANI, C.E.A.; SILVA, A.R.B. Demanda energética e eficiência da distribuição de sementes de milho sob variação de velocidade e condição de solo. Engenharia Agrícola, Jaboticabal, v.24, n.1, p.150-7, 2004.

REIS, A.V.; ALONÇO, A.S. Comparativo sobre a precisão funcional de vários mecanismos dosadores estudados no Brasil entre os anos de 1989 e 2000. In: CONGRESSO BRASILEIRO DE ENGENHARIA AGRÍCOLA, 30., 2001, Foz do Iguaçu. Anais... Foz do Iguaçu: Sociedade Brasileira de Engenharia Agrícola, 2001. 1 CD-ROM.

SILVA, J.G.; KLUTHCOUSKI, J.; SILVEIRA, P.M. Desempenho de uma semeadora-adubadora no estabelecimento e na produtividade da cultura do milho sob plantio direto. Scientia Agrícola, Piracicaba, v.57, n.1, p.7-12, 2000.

SILVA, S.L. Avaliação de semeadoras para plantio direto: demanda energética, distribuição longitudinal e profundidade de deposição de sementes em diferentes velocidades de deslocamento. 2000. 123 f. Tese (Doutorado em Energia na Agricultura) - Faculdade de Ciências Agronômicas, Universidade Estadual Paulista, Botucatu, 2000. 